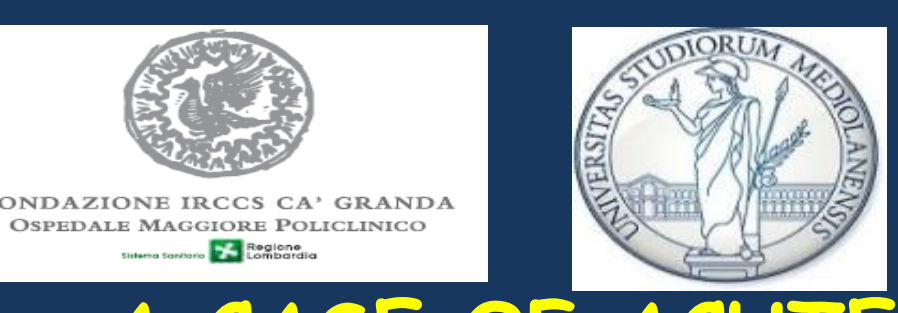

\title{
A CASE OF ACUTE OSTEOYELITIS DUE TO PANTON- VALENTINE LEUKOCIDIN (PVL) - POSITIVE COMMUNITY- ACQUIRED METHICILLIN-RESISTANT STAPHYLOCOCCUS AUREUS (MRSA) IN 3-YEARS-OLD CHILD
}

Tagliabue $C^{1}$, Bosis $S^{1}$, Pinzani $R^{1}$, Marchisio $P^{1}$

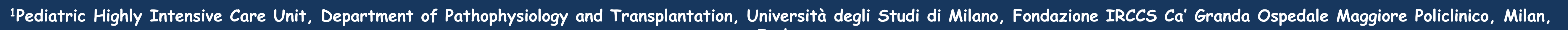
Italy:

\section{BACKGROUND}

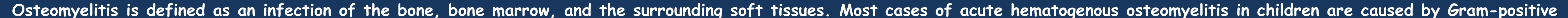

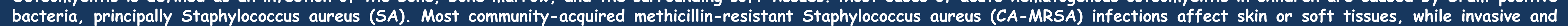

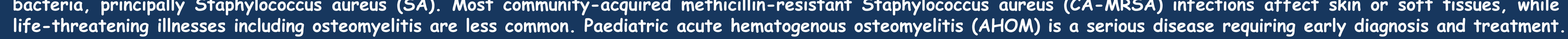

\section{CASE REPORT}

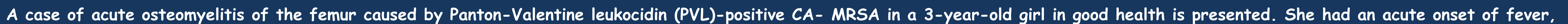

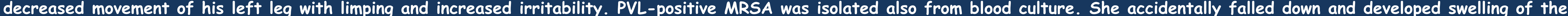

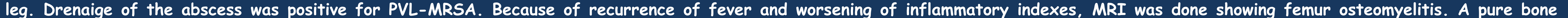

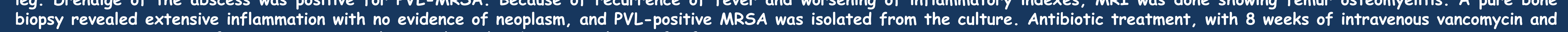
meropenem. One years after treatment completion, there has been no relapse of infection.

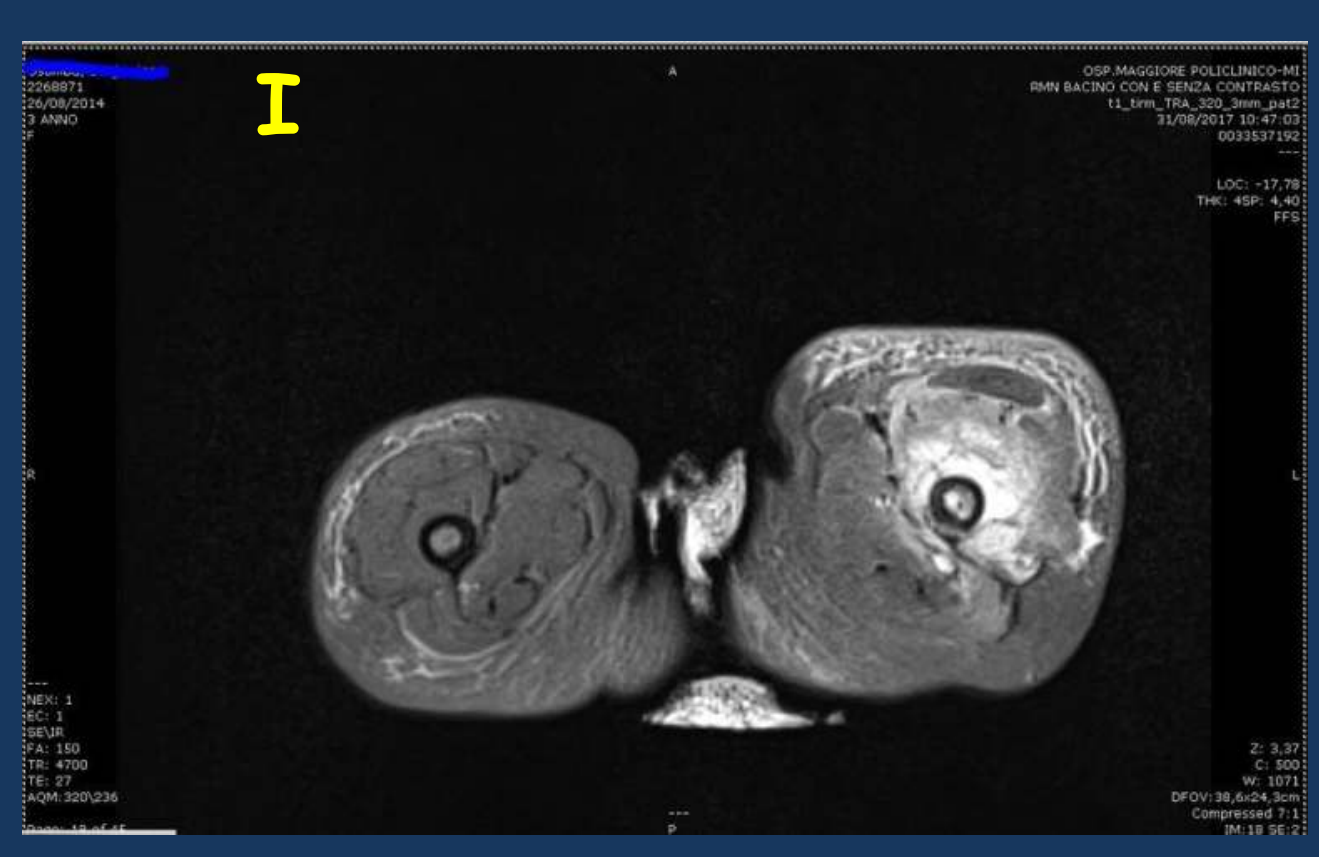

MRI AFTER 2 MONTHS OF TX

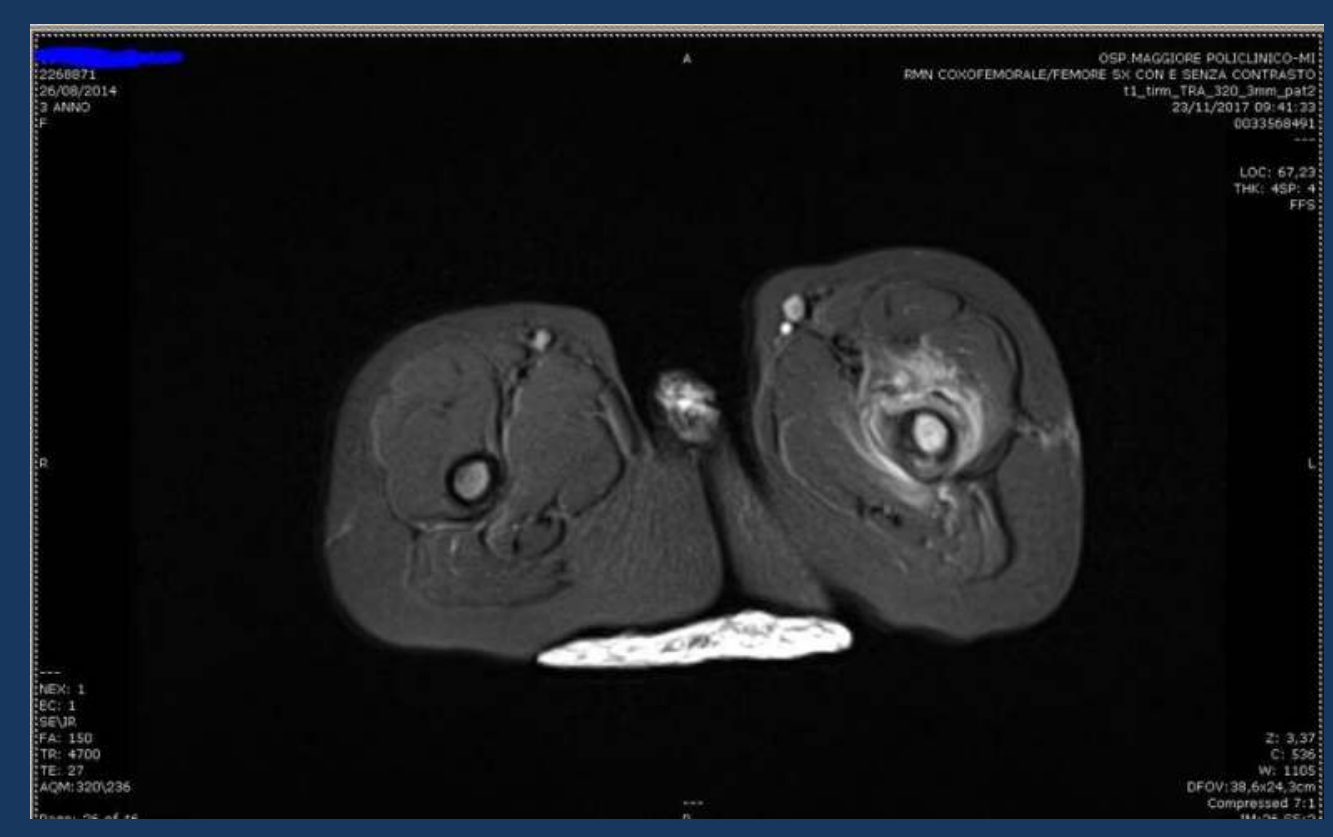

\section{INITIAL MRI}
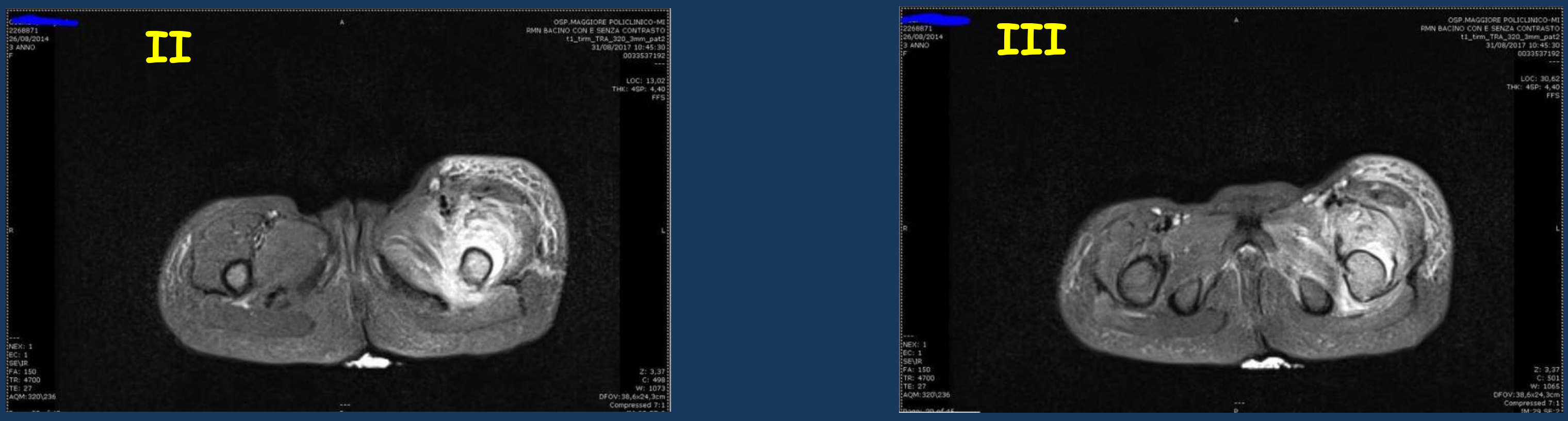

MRI AFTER 1 YEAR
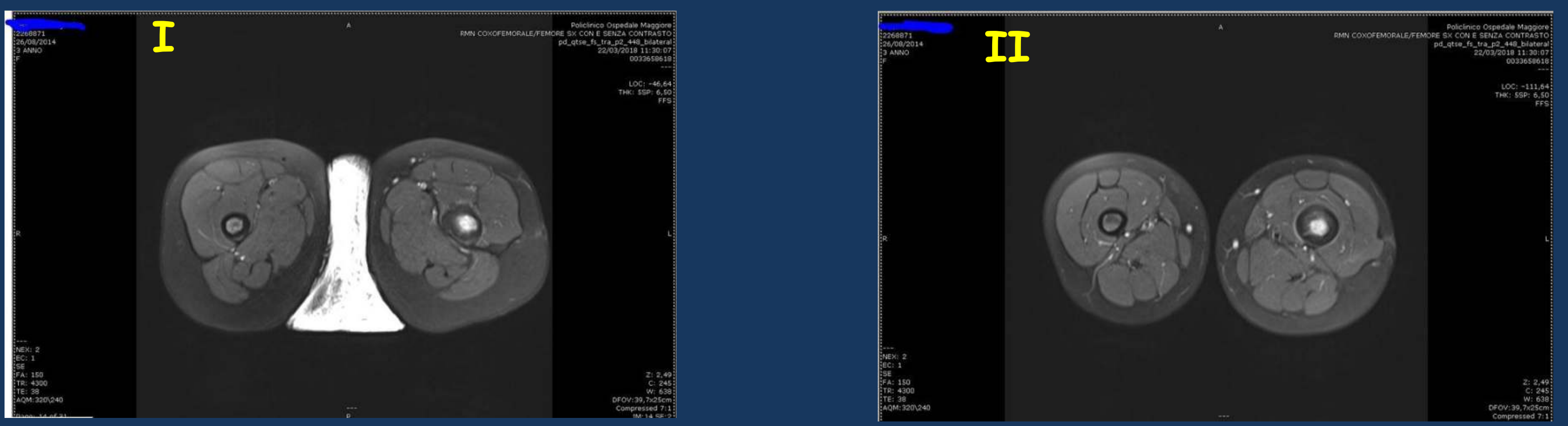

CONCLUSIONS

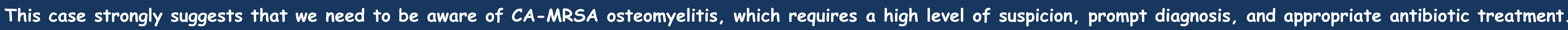

